\title{
Cerebral Oxidative Metabolism during Hypothermia and Circulatory Arrest in Newborn Dogs
}

\author{
JEROME Y. YAGER, ROBERT M. BRUCKLACHER, DENNIS J. MUJSCE, AND \\ ROBERT C. VANNUCCI \\ Department of Pediatrics (Neurology and Neonatology), The Pennsylvania State University College of Medicine,
} The Milton S. Hershey Medical Center, Hershey, Pennsylvania 17033

\begin{abstract}
To ascertain the alterations in cerebral oxidative and energy metabolism that occur during hypothermic circulatory arrest, nitrous oxide-anesthetized, paralyzed, and artificially ventilated newborn dogs were surface cooled to $18-20^{\circ} \mathrm{C}$, after which their hearts were arrested with $\mathrm{KCl}$. At 10, 30, 60, and $105 \mathrm{~min}$ of circulatory arrest, their brains were prepared by in situ freezing for the regional analysis of glycolytic intermediates and highenergy phosphate reserves. Hypothermia alone was associated with optimal preservation of labile metabolites in brain, even in caudal brainstem and cerebellum, compared with barbiturate-anesthetized littermates. After onset of hypothermic circulatory arrest, glucose decreased progressively in cerebral cortex, caudate nucleus, hippocampus, and subcortical white matter to negligible levels by 30 min. Pyruvate increased transiently $(+50 \%)$ at $10 \mathrm{~min}$, whereas lactate increased and plateaued $(10-11 \mathrm{mmol} / \mathrm{kg})$ at 30 $\mathrm{min}$. The disproportionate increases in pyruvate and lactate resulted in a progressive rise in the lactate/pyruvate ratio. Phosphocreatine fell precipitously to $<0.5 \mathrm{mmol} / \mathrm{kg}$ in all structures, with a preservation of ATP for the first $10 \mathrm{~min}$ of cerebral ischemia. Thereafter, ATP decreased to $<0.1$ $\mathrm{mmol} / \mathrm{kg}$ in cerebral cortex and between 0.1 and $0.2 \mathrm{mmol} /$ $\mathrm{kg}$ in caudate nucleus, hippocampus, and white matter. Total adenine nucleotides (ATP + ADP + AMP) were partially depleted by $30 \mathrm{~min}$ in the gray matter structures but were unchanged from control for $60 \mathrm{~min}$ in white matter. The findings showed a direct correlation between preservation of cerebral energy stores during hypothermic circulatory arrest and the selective resistance of subcortical white matter to ischemic damage. However, no such correlation existed for the hippocampus, in which other factors must influence the resistance of this structure to ischemic injury during hypothermia. (Pediatr Res 32: 547-552, 1992)
\end{abstract}

\section{Abbreviations}

$\mathrm{PaO}_{2}$, arterial oxygen tension

$\mathrm{PaCO}_{2}$, arterial carbon dioxide tension pHa, arterial pH

PCr, phosphocreatine

MABP, mean arterial blood pressure

Received February 21, 1992; accepted July 8, 1992

Correspondence: Robert C. Vannucci, M.D. Department of Pediatrics, P.O. Box 850, The Milton S. Hershey Medical Center, Hershey, PA 17033.

Supported by Grant No. HD 26144 from The National Institute of Child Health and Human Development (R.C.V.). J.Y.Y. was the recipient of a Medical Research Council Fellowship Award (Canada)
Hypothermic circulatory arrest has become an established procedure for the operative correction of congenital heart anomalies in infants and children (1). Despite the prevalence of its use in clinical practice, little basic research has been conducted to investigate the protective influence of hypothermia superimposed upon systemic hypoxia, hypotension, or cardiac arrest in perinatal animals (2-5). Accordingly, we have developed a model of hypothermic circulatory arrest in the newborn dog; the neuropathologic consequence thereof is now well documented $(6,7)$. Specifically, newborn dogs subjected to hypothermic circulatory arrest of $1.0 \mathrm{~h}$ duration exhibit no brain damage at 4 or $24 \mathrm{~h}$ of recovery, whereas puppies arrested for $1.5 \mathrm{~h}$ or longer show progressively increasing ischemic injury to selectively vulnerable structures. It is not known just how long a human infant can tolerate hypothermic circulatory arrest, although clinical studies suggest a "safe" interval (60-75 min) similar to that of the newborn dog $(8-10)$.

In the present communication, we describe the results of an investigation conducted in parallel with neuropathologic studies to ascertain the nature and extent of alterations in cerebral carbohydrate and energy metabolism during hypothermia alone and during hypothermic circulatory arrest. A major objective of the study was to correlate changes in regional metabolic activity during hypothermic cerebral ischemia with the known sensitivity (or resistance) of specific brain structures to ischemic damage.

\section{MATERIALS AND METHODS}

Animal preparation. Pregnant mongrel dogs were purchased from a local breeder and maintained in separate kennels. Newborn puppies, delivered vaginally, were maintained with their bitches until time of experimentation between 2 and $7 \mathrm{~d}$ of postnatal age. The newborn dogs were anesthetized with halothane (4\% induction; $1-1.5 \%$ maintenance), during which they were tracheostomized, paralyzed with pancuronium bromide $(1.5 \mathrm{mg} / \mathrm{kg}$ body weight), and artificially ventilated with a gas mixture of $30 \%$ oxygen $-70 \%$ nitrous oxide. Duration of the halothane exposure did not exceed $5 \mathrm{~min}$. Under local anesthesia ( $1 \%$ procaine $\mathrm{HCl}$ ), a femoral artery was cannulated with polyethylene tubing (PE-60), which was connected via a Statham transducer (Gould Inc., Oxnard, CA) to a dynographic recorder (model R 711; Beckman Instruments, Inc., Fullerton, CA) to monitor heart rate and systemic blood pressure. A side arm of the arterial catheter allowed for the intermittent collection $(0.2$ $\mathrm{mL}$ ) of blood for analysis of $\mathrm{PaO}_{2}, \mathrm{PaCO}_{2}$, and $\mathrm{pHa}$ on a microoxygen and acid-base analyzer (model ABL 30; Radiometer America, Inc., Westlake, $\mathrm{OH}$ ). Oxygen and acid-base balance were maintained within a narrow range $\left[\mathrm{PaCO}_{2}=4.4-5.6 \mathrm{kPa}\right.$ $\left.(33-42 \mathrm{~mm} \mathrm{Hg}) ; \mathrm{pHa}=7.35-7.42 ; \mathrm{PaO}_{2}>8.0 \mathrm{kPa}(60 \mathrm{~mm} \mathrm{Hg})\right]$ by intermittent adjustments of tidal volume $( \pm 1 \mathrm{~mL} / 100 \mathrm{~g}$ body weight) and ventilatory rate $( \pm 40 / \mathrm{min})$. A femoral vein also was 
cannulated as an access route for infusion of drugs. Body temperature was monitored by means of a rectal probe attached to a servo-controlled heating lamp.

Induction of hypothermic circulatory arrest. Once steady state arterial normoxia and acid-base balance were achieved, the newborn dogs $(n=11)$ were gently positioned prone on a plastic bag containing crushed ice, and additional ice packs were applied to the back and head. Rectal temperature was continuously monitored during the cooling period, and the ice packs removed when the temperature approached $20^{\circ} \mathrm{C}$. No adjustments in tidal volume or ventilatory rate were made during or after the cooling process. Rectal temperature was maintained between 18 and $20^{\circ} \mathrm{C}$ by occasionally applying ice packs to the lateral aspects of the chest and abdomen.

Once the cooling process was complete, the heart of each newborn dog was arrested by the i.v. administration of $\mathrm{KCl}(25$ $\mathrm{mmol} / \mathrm{L})$ in a small volume $(2-3 \mathrm{~mL})$. Artificial ventilation was discontinued simultaneous with the cardiac arrest. Complete circulatory arrest was verified by the absence of spontaneous heart rate and systemic blood pressure monitored on the dynograph. The animals remained asystolic for either $10(n=3), 30$ $(n=3), 60(n=3)$, or $105(n=2)$ min.

During the course of hypothermic circulatory arrest, the scalp of each newborn dog was incised along the sagittal suture under local anesthesia. A bottomless plastic cup was then secured with sutures to the exposed calvarium for freezing the brain by an in situ technique (11). Transcalvarial freezing of the brain was complete in 5 to $7 \mathrm{~min}$, after which the animals were decapitated into liquid nitrogen, and the frozen head was stored at $-70^{\circ} \mathrm{C}$ for subsequent processing.

The head of each newborn dog was sectioned under liquid nitrogen in the coronal plane to expose multiple surfaces of the brain. Samples (60-100 mg) of cerebral cortex, subcortical white matter, hippocampus, and caudate nucleus as well as brainstem and cerebellum in selected animals were dissected in a cold box set at $-20^{\circ} \mathrm{C}$ and powdered under liquid nitrogen. Weighed samples of brain powder were extracted into $3 \mathrm{M}$ perchloric acid as previously described (12). Arterial blood specimens $(0.02 \mathrm{~mL})$ for glucose and lactate determinations were immediately extracted into ice-cold $0.5 \mathrm{M}$ perchloric acid.

Glycolytic intermediates and high-energy phosphate reserves in brain and blood were determined fluorometrically using pyridine nucleotides and appropriate enzymes. The methods for glucose, pyruvate, phosphocreatine (PCr), ATP, ADP, and AMP were essentially as described by Lowry and Passonneau (13). Lactate was measured as previously reported (12).

Control animals. Three groups of control animals were used in the present investigation. One group $(n=4)$ consisted of newborn dogs that were rendered hypothermic without cardiac arrest. The second set of controls $(n=4)$ consisted of littermates to those undergoing hypothermia, in which body temperature was maintained at $37^{\circ} \mathrm{C}$ and anesthesia was accomplished with the slow i.v. infusion of pentobarbital $(60-80 \mathrm{mg} / \mathrm{kg})$ adequate to produce systemic hypotension to a degree identical to that of the hypothermic controls. The third group of controls $(n=3)$ consisted of puppies maintained at $37^{\circ} \mathrm{C}$ in which pentobarbital $(25-30 \mathrm{mg} / \mathrm{kg})$ was infused i.v. slowly to prevent systemic hypotension. After transcalvarial freezing, all control animals (normothermia and hypothermia) received a lethal injection of pentobarbital.

Cerebral energy use (cerebral metabolic rate). Cerebral energy use-cerebral metabolic rate-during hypothermia was calculated from the changes in the concentrations of ATP, ADP, PCr, glucose, and lactate that occurred during the total cerebral ischemia that takes place during the early phase $(30 \mathrm{~min})$ of hypothermic circulatory arrest according to an equation described by Gatfield et al. (14) ( represents the high energy phosphate bond): $\Delta \sim \mathrm{P}=2 \Delta \mathrm{ATP}+\Delta \mathrm{ADP}+\Delta \mathrm{PCr}+2 \Delta$ glucose +1.45 ( $\Delta$ lactate $-2 \Delta$ glucose).

Statistical analysis. Statistical analysis of the data was accom- plished using one-way analysis of variance and analysis of variance for sequential data.

Institutional approval. The experiments described here were reviewed by the Animal Care and Use Committee of The Pennsylvania State University School of Medicine and approved on August 8, 1987.

\section{RESULTS}

Systemic physiologic variables. Systemic physiologic measurements were conducted sequentially during both normothermia and hypothermia in the 11 newborn dogs that underwent circulatory arrest (Table 1). During hypothermia, MABP and heart rate decreased to 72 and $31 \%$ of the normothermic values, respectively. $\mathrm{PaCO}_{2}$ also decreased $(-16 \%)$, whereas $\mathrm{PaO}_{2}$ essentially doubled $\left(\mathrm{PaO}_{2}, \mathrm{PaCO}_{2}\right.$, and $\mathrm{pHa}$ were measured at $\left.37^{\circ} \mathrm{C}\right)$ (15). Despite the lower $\mathrm{PaCO}_{2}$ and the absence of a lactacidemia, pHa during hypothermia was unchanged from the normothermic value.

Systemic physiologic variables of the three groups of control puppies, obtained immediately before transcalvarial freezing, are shown in Table 2. The major differences in the three groups related to systemic blood pressure, in which the hypothermic and barbiturate/hypotensive animals exhibited essentially identical MABP, whereas the barbiturate/normotensive animals maintained their MABP within $90 \%$ of the value obtained during normothermia and nitrous oxide anesthesia (Table 1). All systemic physiologic measurements in the hypothermic control animals were comparable to those also during hypothermia in the puppies subjected to circulatory arrest.

Table 1. Systemic physiologic measurements during normothermia and hypothermia in newborn dogs subjected to circulatory arrest*

\begin{tabular}{lcc}
\hline \multicolumn{1}{c}{ Variable } & Normothermia & Hypothermia \\
\hline MABP (torr) & $71 \pm 3$ & $51 \pm 5 \dagger$ \\
Heart rate $(\mathrm{bpm})$ & $239 \pm 6$ & $75 \pm 3 \dagger$ \\
$\mathrm{PaO}_{2}(\mathrm{kPa})$ & $12.5 \pm 1.0$ & $24 \pm 2 \dagger$ \\
$\mathrm{PaCO}_{2}(\mathrm{kPa})$ & $4.9 \pm 0.1$ & $4.1 \pm 0.1 \dagger$ \\
$\mathrm{pHa}$ & $7.38 \pm 0.01$ & $7.38 \pm 0.01$ \\
Glucose $(\mathrm{mmol} / \mathrm{L})$ & $8.7 \pm 0.5$ & $10.8 \pm 0.9$ \\
Lactate $(\mathrm{mmol} / \mathrm{L})$ & $1.4 \pm 0.2$ & $1.7 \pm 0.1 \ddagger$ \\
\hline
\end{tabular}

* Values represent means \pm SEM of two sequential measurements 75 $90 \mathrm{~min}$ apart in 11 newborn dogs. Measurements were obtained during normothermia immediately before surface cooling and during hypothermia immediately before circulatory arrest. $\mathrm{PaO}_{2}, \mathrm{PaCO}_{2}$, and $\mathrm{pHa}$ were measured at $37^{\circ} \mathrm{C}$.

$\dagger p<0.001$ compared to normothermia

$\forall p<0.05$ compared to normothermia.

Table 2. Systemic physiologic measurements in hypothermic and in barbiturate-anesthetized newborn dogs*

\begin{tabular}{lccc}
\hline & & \multicolumn{2}{c}{ Barbiturate } \\
\cline { 3 - 4 } \multicolumn{1}{c}{ Variable } & $\begin{array}{c}\text { Hypothermia } \\
(n=4)\end{array}$ & $\begin{array}{c}\text { Normotension } \\
(n=3)\end{array}$ & $\begin{array}{c}\text { Hypotension } \\
(n=4)\end{array}$ \\
\hline $\mathrm{MABP}($ torr $)$ & $33 \pm 6$ & $66 \pm 5 \dagger$ & $30 \pm 6 \ddagger$ \\
$\mathrm{Heart} \mathrm{ratc}(\mathrm{bpm})$ & $65 \pm 2$ & $222 \pm 18 \dagger$ & $161 \pm 21 \dagger$ \\
$\mathrm{PaO}_{2}(\mathrm{kPa})$ & $35 \pm 2$ & $18 \pm 2 \dagger$ & $13 \pm 2 \dagger$ \\
$\mathrm{PaCO}(\mathrm{kPa})$ & $3.6 \pm 0.5$ & $4.5 \pm 0.4$ & $4.4 \pm 0.1$ \\
$\mathrm{pHa}$ & $7.46 \pm 0.02$ & $7.38 \pm 0.01$ & $7.43 \pm 0.01 \dagger$ \\
$\mathrm{Glucose}(\mathrm{mmol} / \mathrm{L})$ & $10.1 \pm 1.9$ & $9.2 \pm 1.2$ & $9.5 \pm 0.7$ \\
Lactate $(\mathrm{mmol} / \mathrm{L})$ & $2.1 \pm 0.4$ & $1.5 \pm 0.3$ & $2.1 \pm 0.4$ \\
\hline
\end{tabular}

* Values represent means \pm SEM for three to four newborn dogs in each group. Measurements were obtained immediately before transcalvarial freezing of the brains. $\mathrm{PaO}_{2}, \mathrm{PaCO}_{2}$, and $\mathrm{pHa}$ were measured at $37^{\circ} \mathrm{C}$.

$+p<0.05$ compared to hypothermia.

$\$ p<0.05$ compared to barbiturate normotension. 
Cerebral metabolism in control and hypothermic animals. Unpublished studies from our laboratory have shown that the in situ brain freezing of normothermic, nitrous oxide-anesthetized dogs leads to substantial autolytic changes in the concentrations of labile tissue constituents ("freezing artifact"), especially of the deeper regions of the cerebral hemispheres, the brainstem and cerebellum (16). Therefore, three newborn dogs were surgically prepared as described in Materials and Methods, after which they were slowly anesthetized with pentobarbital over 10 to 15 $\mathrm{min}$. The dosage of pentobarbital $(25-30 \mathrm{mg} / \mathrm{kg})$ was adequate to produce deep surgical anesthesia without significant hypotension. Four additional dogs received pentobarbital $(60-80 \mathrm{mg} / \mathrm{kg})$ over 10 to $15 \mathrm{~min}$ adequate to produce a reduction in systemic blood pressure equivalent to that of the hypothermic animals (Table 2). Transcalvarial freezing of the brain was then accomplished, and tissue specimens were prepared and assayed for glycolytic intermediates and high-energy reserves. Previous studies in adult and perinatal animals suggest that barbiturate anesthesia optimally preserves labile constituents in brain with or without associated systemic hypotension $(15,17)$.

A regional comparison of the concentrations of glycolytic intermediates and high-energy phosphate reserves in newborn dogs rendered hypothermic indicated that labile metabolites were reasonably well preserved even in the brainstem and cerebellar structures (Fig. 1). Such was not the case for the pentobarbital anesthetized animals (either normotensive or hypotensive), in
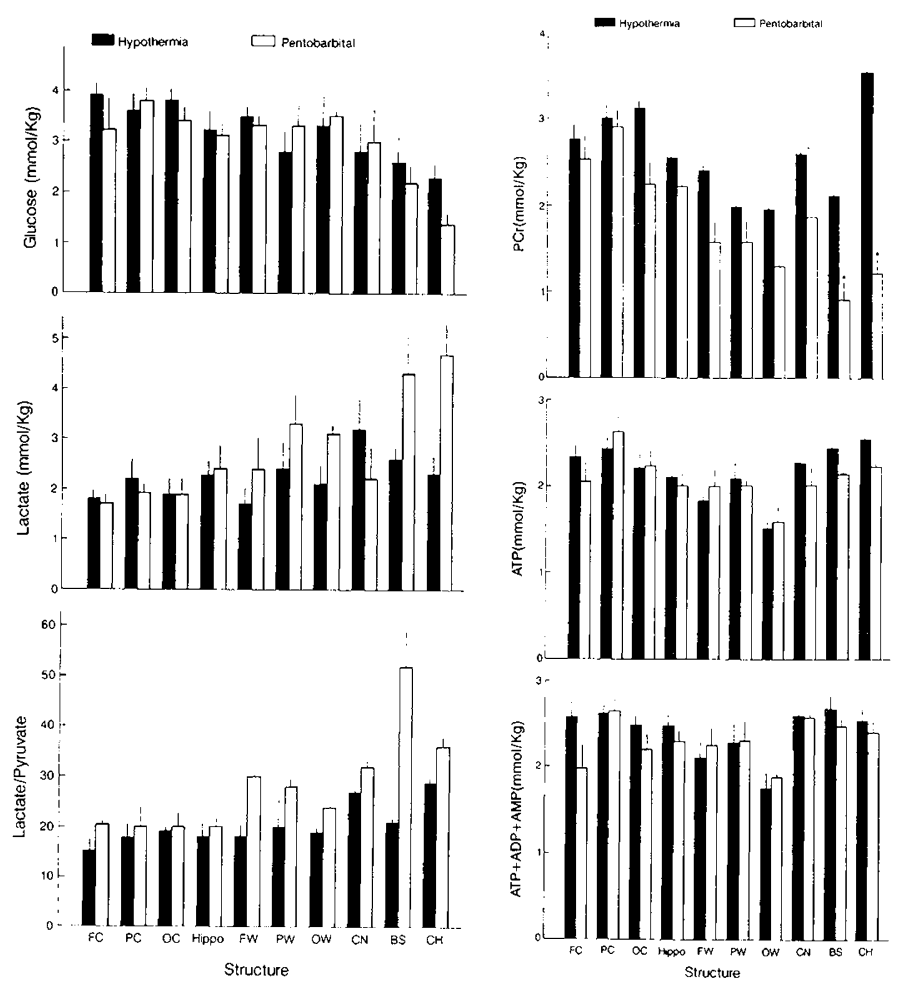

Fig. 1. Glycolytic intermediates and high-energy reserves in newborn dog brain during hypothermia or barbiturate anesthesia. Hypothermia was effected by surface cooling to $18-20^{\circ} \mathrm{C}$, and barbiturate anesthesia was produced by the i.v. injection of pentobarbital adequate to produce systemic hypotension comparable to that of the hypothermic animals. Bars represent means for four newborn dogs in each group; vertical lines denote \pm 1 SEM. ${ }^{*}, p<0.05$ compared to hypothermia. Not shown are metabolite concentrations derived from three puppies that were anesthetized with pentobarbital injected slowly to prevent systemic hypotension. These metabolite levels were similar to and not statistically different from those obtained in the barbiturate/hypotensive animals. Abbreviations: $F C$, frontal cortex; $P C$, parietal cortex; $O C$, occipital cortex; Hippo, hippocampus; $F W$, frontal white; $P W$, parietal white; $O W$, occipital white; $C N$, caudate nucleus; $B S$, brainstem; and $C H$, cerebellar hemisphere. which alterations in tissue constituents were apparent, especially in the brainstem and cerebellum. These perturbations included variable increases in lactate and associated lactate/pyruvate ratios $(p>0.05$ ) combined with 58 and $64 \%$ reductions in $\mathrm{PCr}$ of the brainstem and cerebellum, respectively $(p<0.05)$, compared to hypothermia. However, the freezing artifact of these structures was inadequate to disrupt energy metabolism further, inasmuch as concentrations of ATP and the total adenine nucleotide pool $(\mathrm{ATP}+\mathrm{ADP}+\mathrm{AMP})$ were not significantly different in any analyzed structure of the hypothermic and barbiturate-anesthetized animals. Accordingly, hypothermia to a core temperature of $20^{\circ} \mathrm{C}$ appears to have preserved labile constituents in brain equal to or better than surgical anesthesia with pentobarbital.

Cerebral metabolism during hypothermic circulatory arrest. A total of 11 newborn dogs were subjected to either $10,30,60$, or 105 min of hypothermic circulatory arrest, during which their brains were frozen for analysis of glycolytic intermediates and high-energy phosphate reserves. Alterations in oxidative and energy metabolism of four representative regions of forebrain are shown in Figures 2 and 3; these structures were chosen because
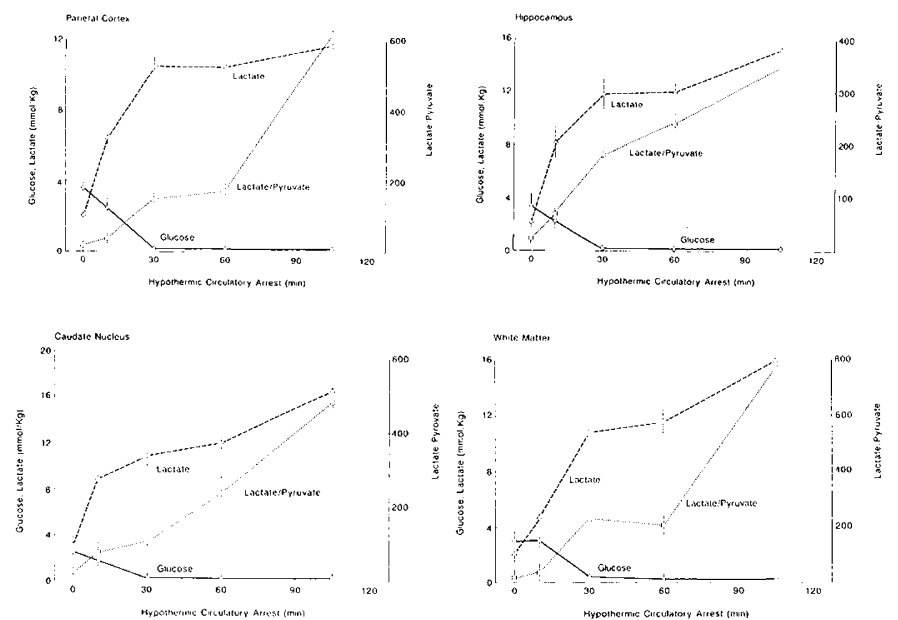

Fig. 2. Glycolytic intermediates in four regions of newborn dog brain during hypothermic circulatory arrest. Symbols represent means of three brains at 10,30, and $60 \mathrm{~min}$ and of two brains at $105 \mathrm{~min}$ of cardiac arrest; vertical lines denote \pm 1 SEM. Zero time values derived from Figure 1 (hypothermia).
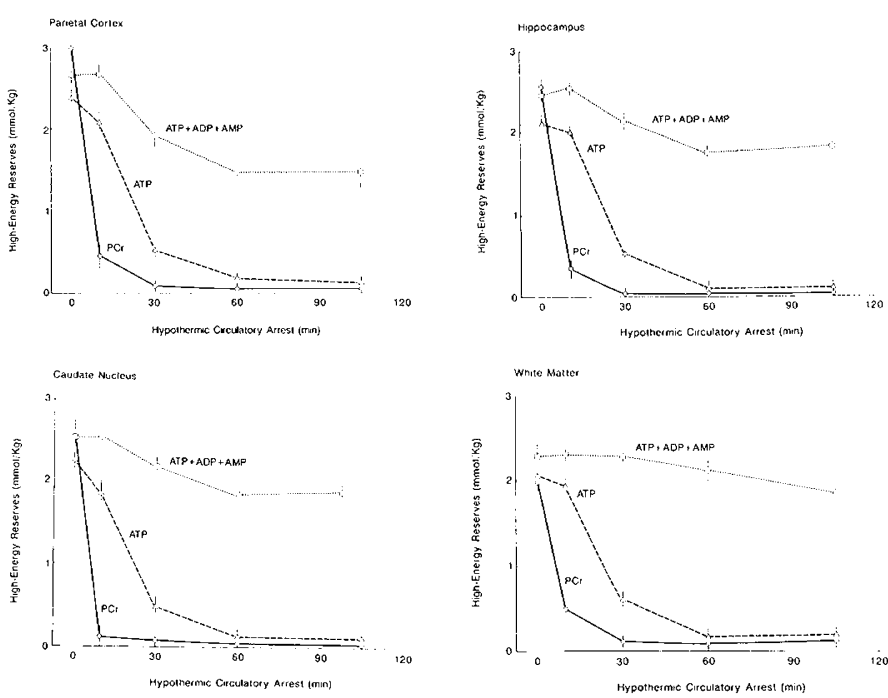

Fig. 3. High-energy reserves in four regions of newborn dog brain during hypothermic circulatory arrest. Symbols represent means of three brains at 10,30, and $60 \mathrm{~min}$ and of two brains at $105 \mathrm{~min}$ of cardiac arrest; vertical lines denote \pm 1 SEM. Zero time values derived from Figure 1 (hypothermia). 
of their known respective vulnerabilities to ischemic damage resulting from hypothermic circulatory arrest. Specifically, cerebral cortex and caudate nucleus appear most sensitive, hippocampus less sensitive, and subcortical white matter most resistant (for details, see Discussion).

In all structures analyzed, hypothermic circulatory arrest was associated with a progressive decline in tissue glucose to near negligible levels by $30 \mathrm{~min}$ of total cerebral ischemia. As glucose decreased, lactate increased, at least initially, indicating a shift from aerobic to anaerobic glycolysis. Pyruvate (not shown) remained unchanged from hypothermic control values $(0.09-0.14$ $\mathrm{mmol} / \mathrm{kg}$ ) for up to $60 \mathrm{~min}$ of circulatory arrest, thereafter decreasing to concentrations ranging from 0.02 to $0.03 \mathrm{mmol} /$ $\mathrm{kg}$. The increasing lactate combined with unchanging or decreasing pyruvate resulted in progressive increases in lactate/pyruvate ratios. That lactate in parietal cortex plateaued at $60 \mathrm{~min}$ of hypothermic circulatory arrest most likely reflects the total exhaustion of tissue carbohydrate stores, whereas in other structures a small amount of residual glucose and glycogen (not measured) possibly contributed to the further rise in lactate between 60 and $105 \mathrm{~min}$.

Because the brain is totally ischemic (no arterial inflow or venous outflow) during hypothermic circulatory arrest, the maximal glycolytic flux can be calculated from the extent of lactate accumulation for any individual structure (Table 3). The maximal glycolytic rates of parietal cortex, hippocampus, and caudate nucleus were comparable, whereas the glycolytic rate of subcortical white matter was $35-53 \%$ less than those of the gray matter structures $(p<0.05)$.

Hypothermic circulatory arrest also was associated with major perturbations in the energy status of newborn dog brain. PCr fell precipitously in all analyzed structures, with a relative preservation of ATP for the first $10 \mathrm{~min}$ of cerebral ischemia. Thereafter, ATP also decreased to concentrations $<0.1 \mathrm{mmol} / \mathrm{kg}$ in parietal cortex and between 0.1 and $0.2 \mathrm{mmol} / \mathrm{kg}$ in hippocampus, caudate nucleus, and white matter by $60 \mathrm{~min}$. Proportionate increases in ADP and AMP to maintain total adenine nucleotides (ATP + ADP + AMP) within the normal range occurred for only $10 \mathrm{~min}$ in parietal cortex, hippocampus, and caudate nucleus, whereas the total adenine nucleotide pool was unchanged for up to $60 \mathrm{~min}$ in white matter. After these intervals, ADP exhibited a secondary decline, whereas AMP continued to accumulate but to an extent inadequate to maintain the total adenine nucleotide pool stable.

Cerebral energy use during hypothermia. During the total cerebral ischemia that occurs after the onset of hypothermic circulatory arrest, cerebral functional activity must be maintained at the expense of endogenous high-energy phosphate stores and by the energy derivable from the anaerobic breakdown of glucose and glycogen to lactic acid. Thus, from measurements of the changes in these compounds early after the onset of

Table 3. Maximal glycolytic and energy use rates of newborn dog brain during hypothermia*

\begin{tabular}{lcc}
\hline \multicolumn{1}{c}{ Structure } & $\begin{array}{c}\text { Maximal } \\
\text { glycolytic rate } \\
(\mathrm{mmol} / \mathrm{kg} / \mathrm{min})\end{array}$ & $\begin{array}{c}\text { Energy use } \\
(\mathrm{mmol} \sim \mathrm{P} / \mathrm{kg} / \mathrm{min})\end{array}$ \\
\hline Cerebral cortex & $0.43 \pm 0.08$ & $0.69 \pm 0.09$ \\
Hippocampus & $0.61 \pm 0.13$ & $0.75 \pm 0.13$ \\
Caudate nucleus & $0.58 \pm 0.06$ & $0.76 \pm 0.12$ \\
White matter & $0.27 \pm 0.03 \ddagger$ & $0.52 \pm 0.03$ \\
\hline
\end{tabular}

* Maximal glycolytic flux for each brain structure was calculated from the changes in tissue lactate concentrations during the first $10 \mathrm{~min}$ of hypothermic circulatory arrest (Fig. 2). Energy use was calculated from the changes in tissue glucose, lactate, PCr, ATP, and ADP during the first $30 \mathrm{~min}$ of hypothermic circulatory arrest, according to the equation described in the text (see Figs. 2-4). Values represent means \pm SEM.

$\dagger \sim$ represents the high energy phosphate bond.

$\$ p<0.05$ compared to all gray matter structures.
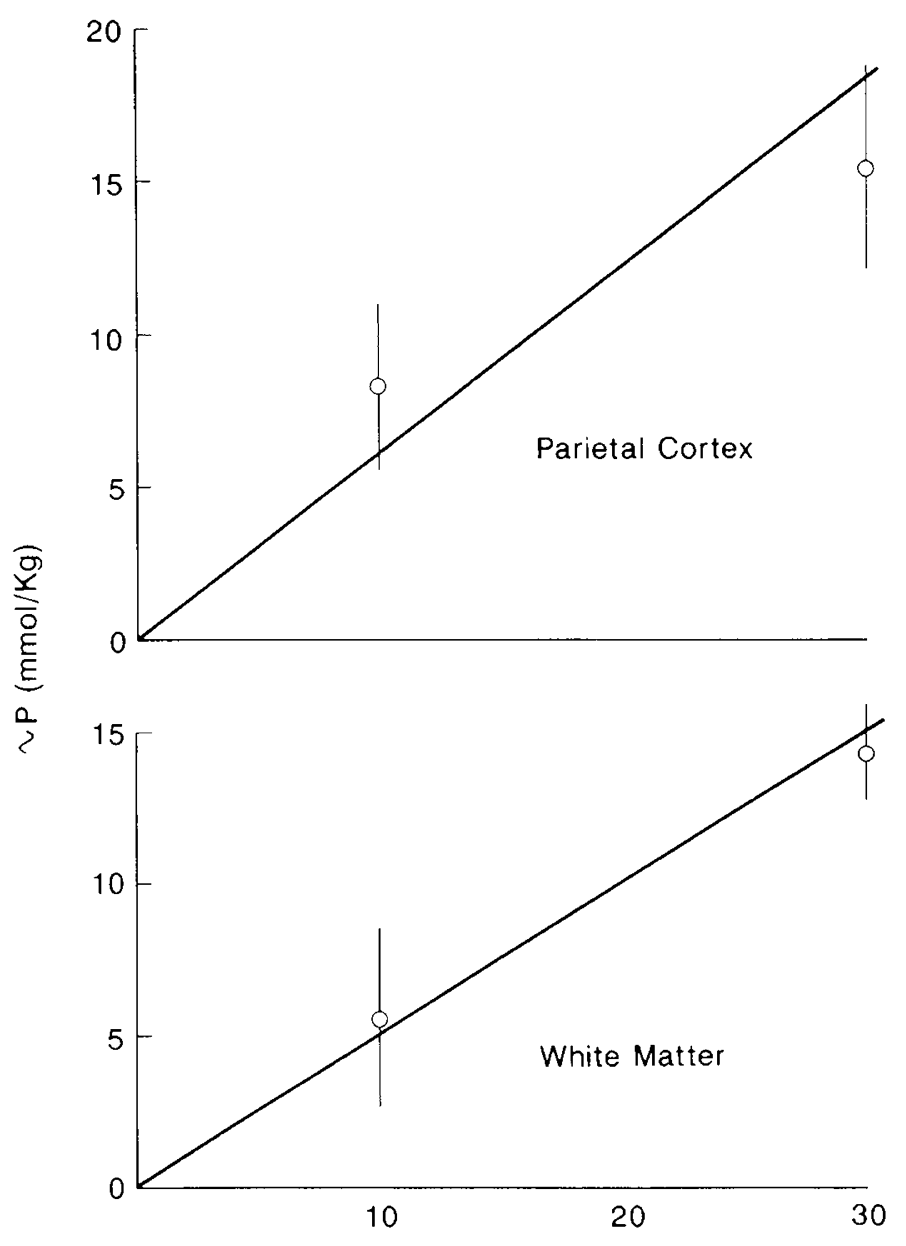

Time of Ischemia ( $\mathrm{min})$

Fig. 4. Calculated energy use in parietal cortex and subcortical white matter of newborn dog brain during hypothermia. Symbols represent values $\pm 1 \mathrm{SD}$ calculated from the data shown in Figures 2 and 3 and by the formula described in the text. Energy use rates ( $\mathrm{mmol} \sim \mathrm{P} / \mathrm{kg} / \mathrm{min}$ ) were obtained from the slopes of the lines (see Table 3 ). $\sim$ represents the high energy phosphate bond.

ischemia, the rate of cerebral energy use or the cerebral metabolic rate during hypothermia-before circulatory arrest-can be estimated (18). Because glycogen concentrations are low in newborn dog brain (19), energy use was calculated according to the equation described in Materials and Methods.

The rate of energy use (metabolic rate) of cerebral cortex during hypothermia was $0.69 \mathrm{mmol} \sim \mathrm{P} / \mathrm{kg} / \mathrm{min}$, a rate that is $31 \%$ of the rate for newborn dog cerebral cortex during normothermia (20) (Table 3). Energy use rates of the hippocampus and caudate nucleus were comparable to that of cerebral cortex, whereas the use rate of white matter was slightly lower than those of the gray matter structures, although not significantly.

\section{DISCUSSION}

The findings of the present investigation should be interpreted in relation to the known neuropathologic responses of newborn dogs to hypothermic circulatory arrest of increasing durations. In an investigation published in this journal, nitrous oxideanesthetized and artificially ventilated puppies were subjected to hypothermic circulatory arrest for $1.0,1.5$, and $2.0 \mathrm{~h} ; 3-4 \mathrm{~h}$ postresuscitation, they underwent perfusion-fixation of their brains for pathologic analysis (6). No neuropathologic alterations were seen in puppies arrested for $1.0 \mathrm{~h}$, whereas animals arrested for $1.5 \mathrm{~h}$ showed mild-to-moderate damage (selective neuronal 
necrosis) exclusively of the cerebral cortex, and animals arrested for $2.0 \mathrm{~h}$ exhibited severe damage of the cerebral cortex and also injury of the caudate nucleus and hippocampus. In a recently completed investigation, newborn dogs subjected to hypothermic circulatory arrest for $1.0-1.75 \mathrm{~h}$ that were successfully weaned from anesthesia and artificial ventilation were allowed to recover for 18 to $24 \mathrm{~h} \mathrm{(7).} \mathrm{As} \mathrm{in} \mathrm{the} \mathrm{short-term} \mathrm{recovery} \mathrm{study,} \mathrm{three} \mathrm{of}$ three puppies arrested for $1.0 \mathrm{~h}$ exhibited no brain damage, whereas one of three and four of four puppies arrested for 1.5 and $1.75 \mathrm{~h}$, respectively, showed mild-to-moderate tissue injury predominantly of the cerebral cortex but also of the basal ganglia. The hippocampus was spared in these brains. Three dogs arrested for $2.0 \mathrm{~h}$ could not be weaned from ventilation and developed cardiovascular collapse over 4 to $6 \mathrm{~h}$. From the combined studies, we concluded that newborn dogs undergoing hypothermic circulatory arrest for $1.0 \mathrm{~h}$ are fully recoverable and exhibit no brain damage; puppies arrested for $1.75 \mathrm{~h}$ are fully recoverable but exhibit mild-to-moderate brain damage; and puppies arrested for $2.0 \mathrm{~h}$ remain ventilator-dependent and exhibit severe brain damage at 3 to $4 \mathrm{~h}$ after cardiac resuscitation.

Given these neuropathologic considerations, the present investigation was designed to ascertain the extent of alterations in oxidative and energy metabolism during hypothermia and circulatory arrest of intervals known to produce brain damage. The data indicate that hypothermia alone to a core temperature of $18-20^{\circ} \mathrm{C}$ is not associated with any perturbations in cerebral glycolytic intermediates or high-energy reserves; on the contrary, these metabolites are preserved as well as or better than those measured in the brains of newborn dogs anesthetized with pentobarbital, i.e. minimal or no autolytic changes (freezing artifact) (16). Studies in adult animals also have demonstrated that hypothermia has no adverse influence on the energy status of brain tissue, whereas selected glycolytic and tricarboxylic acid intermediates, including pyruvate and lactate, are reduced, suggesting that oxidative metabolic flux has been curtailed by the lower than normal brain temperature $(21-23)$. That oxidative metabolism is reduced is supported by the well-established observation that hypothermia substantially lowers the cerebral metabolic rate for oxygen (24-26).

The data presented herein indicate major perturbations in the oxidative and energy status of newborn dog brain during hypothermic circulatory arrest. A species- and age-specific model of cardiac arrest during normothermia does not exist to allow metabolic comparisons at the two body temperatures. Vannucci and Duffy (11) did subject newborn dogs to normothermic asphyxiation, $10 \mathrm{~min}$ after which MABP had fallen to $20 \mathrm{~mm}$ $\mathrm{Hg}$ and cerebral perfusion was essentially nil. At $10 \mathrm{~min}$ of asphyxia, the magnitude of the decreases in cerebral cortical glucose, PCr, and ATP and the increases in lactate and ADP were comparable to those observed at $30 \mathrm{~min}$ of hypothermic circulatory arrest (present study), in keeping with the approximately $2 / 3$ reduction in cerebral metabolism of newborn dog brain during hypothermia (see Results). A similar 2- to 3-fold prolongation of cerebral energy (ATP) preservation afforded by hypothermia has been described in adult dogs and rabbits undergoing hypothermic circulatory arrest $(27,28)$.

It is apparent from the present and other studies that major perturbations in high-energy phosphate compounds can occur in newborn brain without subsequent tissue injury as long as the interval of cerebral ischemia is relatively short $(11,29)$. Specifically, brain damage does not occur in newborn dogs subjected to $1 \mathrm{~h}$ of hypothermic complete cerebral ischemia $(6,7)$ despite depletion of $\mathrm{PCr}$ and ATP to $0.5-0.7 \%$ and $3-8 \%$ of control levels, respectively (Fig. 3). The findings suggest that it is not just the absolute concentration-below a threshold value-of ATP (or total energy reserves) that predicts ultimate tissue injury but rather the relationship between the extent of the altered concentration and the duration of the energy failure (see also 30) (see below).

A major objective of the present investigation was to correlate regional alterations in metabolic activity and energy reserves during hypothermic circulatory arrest with the known differential vulnerability of specific brain structures to total cerebral ischemia in newborn dogs. In this regard, our neuropathologic studies have shown that cerebral cortex and caudate nucleus are consistently damaged after $1.75 \mathrm{~h}$ of cardiac arrest, whereas the hippocampus shows no or only minor injury (7). White matter is spared, even after $2 \mathrm{~h}$ of cardiac arrest (6). Given the minor differences in cerebral metabolic rate among the gray matter structures (cerebral cortex, caudate nucleus, and hippocampus) during hypothermia (see Table 3), it is unlikely that differences in preischemic metabolic activity per se account for the apparent resistance especially of the hippocampus to ischemic damage. The cerebral metabolic rate of subcortical white matter during hypothermia was $25-32 \%$ lower than those of the gray matter structures, which was associated with a preservation of the total adenine nucleotide pool (ATP + ADP + AMP) for $60 \mathrm{~min}$ or longer. These findings suggest that the resistance of white matter to ischemic injury is at least in part related to its intrinsic low rate of metabolic activity both before and during hypothermic circulatory arrest.

Clearly, factors in addition to altered energy reserves contribute to the selective vulnerability of neuronal populations and especially the hippocampus to ischemic damage, whether during normothermia or hypothermia. However, without a major perturbation in the energy status of the tissue, it is unlikely that such factors, including the generation of oxygen-free radicals, disruption of intracellular calcium homeostasis, and excitatory amino acid neurotoxicity, are influential in rendering specific regions of brain susceptible to ischemic injury $(31-34)$. The role of these and other metabolic factors, occurring postischemia (no reflow, delayed hypoperfusion, uncoupled oxidative phosphorylation), has yet to be defined. These potentially critical events are the focus of future research on our model of perinatal hypothermic circulatory arrest.

\section{REFERENCES}

1. Hickey PR, Anderson NP 1987 Deep hypothermic circulatory arrest: a review of pathophysiology and clinical experience as a basis for anesthetic management. J Cardiothorac Anesthesia 1:137-155

2. Mott JC 1961 The ability of young mammals to withstand total oxygen lack. Br Med Bull 17:144-148

3. Daniel SS, Dawes GS, James LS 1966 Hypothermia and the resuscitation of the asphyxiated fetal rhesus monkeys. J Pediatr 68:45-53

4. Heideger PM, Miller FS, Miller JA 1970 Cerebral and cardiac enzymatic activity and tolerance to asphyxia during maturation in the rabbit. J Physiol 206:25-40

5. Young RSK, Olenginski TP, Yagel SK, Towfighi J 1983 The effect of graded hypothermia on hypoxic-ischemic brain damage: a neuropathologic study in the neonatal rat. Stroke 14:929-934

6. Mujsce DJ, Towfighi J, Vannucci RC 1990 Physiologic and neuropathologic aspects of hypothermic circulatory arrest in newborn dogs. Pediatr Res 28:354-360

7. Mujsce DJ, Towfighi J, Yager JY, Vannucci RC 1992 Neuropathologic aspects of hypothermic circulatory arrest in newborn dogs. Acta Neuropathol (in press)

8. Stevenson JG, Stone EF, Dillard DH 1974 Intellectual development of children subjected to prolonged circulatory arrest during hypothermic open heart surgery in infancy. Circulation 49:54-59

9. Dickinson DF, Sambrooks JE 1979 Intellectual performance in children after circulatory arrest with profound hypothermia in infancy. Arch Dis Child $54: 1-6$

10. Wells FC, Coghill S, Caplan HL 1983 Duration of circulatory arrest does influence the psychological development of children after cardiac operations in early life. J Thorac Cardiovasc Surg 86:823-831

11. Vannucci RC, Duffy TE 1977 Cerebral metabolism in newborn dogs during reversible asphyxia. Ann Neurol 1.528-534

12. Vannucci RC, Duffy TE 1974 The influence of birth on carbohydrate and energy metabolism in rat brain. Am J Physiol 226:933-940

13. Lowry OH, Passonneau JV 1972 A Flexible System of Enzymatic Analysis Academic Press, New York

14. Gatfield PD, Lowry OH, Schulz DW, Passonneau JV 1966 Regional energy reserves in mouse brain and changes with ischemia and anesthesia. $J$ Neurochem 13:185-195

15. Siesjö BK 1978 Brain Energy Metabolism. Wiley, Chichester, England

16. Pontén U, Ratcheson RA, Salford LG, Siesjö BK 1973 Optimal freezing conditions for cerebral metabolites in rats. J Neurochem 21:1127-1138 
17. Vannucci RC, Wolf JW 1978 Oxidative metabolism in fetal rat brain during maternal anesthesia. Anesthesiology 48:238-244

18. Lowry OH, Passonneau JV, Hasselberger FX, Schulz DW 1964 Effect of ischemia on known substrates and cofactors of the glycolytic pathway in brain. J Biol Chem 239:18-30

19. Vannucci RC, Nardis EE, Vannucci SJ, Campbell PA 1981 Cerebral carbohydrate and energy metabolism during hypoglycemia in newborn dogs. Am J Physiol 240:R192-R199

20. Vannucci RC, Hernandez MJ, Wolf JW 1977 Cerebral oxidative metabolism in newborn dogs: comparison of two methods. Ann Neurol 2:265-266

21. Thorn W, Scholl M, Pfleiderer G, Mueldener B 1958 Metabolic processes in the brain at normal and reduced temperatures and under anoxic and ischemic conditions. J Neurochem 2:150-165

22. Brunner EA, Passonneau JV, Molstad C 1971 The effect of volatile anesthetics on levels of metabolites and on metabolic rate in brain. $J$ Neurochem 18:2301-2316

23. Hägerdal M, Harp J, Siesjö BK 1975 Effect of hypothermia upon organic phosphates, glycolytic metabolites, citric acid cycle intermediates and associated amino acids in rat cerebral cortex. J Neurochem 24:743-748

24. Michenfelder JD, Theye RA 1968 Hypothermia: effect on canine brain and whole-body metabolism. Anesthesiology 29:1107-1112

25. Hägerdal M, Harp J, Siesjö BK 1975 The effect of induced hypothermia upon oxygen consumption in the rat brain. J Neurochem 24:311-316

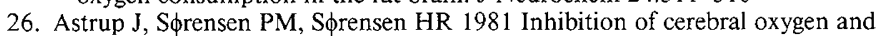

glucose consumption in the dog by hypothermia, pentobarbital and lidocaine. Anesthesiology 55:263-268

27. Kramer RS, Sanders AP, Lesage AM, Woodhall B, Sealy WC 1968 The effect of profound hypothermia on preservation of cerebral ATP content during circulatory arrest. J Thorac Cardiovasc Surg 56:699-709

28. Stocker F, Herschkowitz M, Bossi E, Stoller M, Cross TA, Aue WP, Seelig 1986 Cerebral metabolic studies in situ by ${ }^{31} \mathrm{P}$ nuclear magnetic resonance after hypothermic circulatory arrest. Pediatr Res 20:867-871

29. Vannucci RC, Duffy TE 1976 Cerebral oxidative and energy metabolism of fetal and neonatal rats during anoxia and recovery. Am J Physiol 230:1269_ 1275

30. Welsh FA, Sims RE, Harris VA 1990 Mild hypothermia prevents ischemic injury in gerbil hippocampus. J Cereb Blood Flow Metab 10:557-563

31. Yoshida S, Abe K Busto R, Watson BD, Kogure K, Ginsberg MD 1982 Influence of transient ischemia on lipid-soluble anti-oxidants, free fatty acids and energy metabolites in rat brain. Brain Res 245:307-316

32. Hyslop PA, Hinshaw DB, Halsey WA, Schraufstätter IU, Sauerheber RD, Spragg RG, Jackson JH, Cochrane CG 1988 Mechanisms of oxidant-mediated cell injury. $J$ Biol Chem 263:1665-1675

33. Novelli A, Reilly JA, Lysko PG, Henneberry RC 1988 Glutamate becomes neurotoxic via the N-methyl-D-aspartate receptor when intracellular energy levels are reduced. Brain Res 451:205-212

34. Lipton P, Lobner D 1990 Mechanisms of intracellular accumulation in the $\mathrm{CA} 1$ region of rat hippocampus during anoxia in vitro. Stroke 21:60-64

\section{Announcement}

\section{Manuscripts on Electronic Diskettes}

\section{Preparation of Disks}

Authors are encouraged to submit electronic diskettes of the final version of their manuscripts along with the typed REVISED manuscript. Diskettes produced on IBM or IBM-compatible computers are preferred, but those produced on most Apple/Macintosh or Wang computers can also be converted. The following word processing programs are preferred: XyWrite III Plus, Word Perfect 4.2, 5.0, or 5.1 (IBM or Macintosh), Microsoft Word (IBM or Macintosh), Wang OIS (WPS), and Wordstar (IBM). Among other word processing systems that we can convert are CPT 8000 , MacWrite 2.2 or 4.5 , Display Write 3 or 4 , Multimate, PC Write, Volkswriter, and Write Now. Authors preparing diskettes on Macintosh computers should not use the Fast Save option. Files in ASCII can also be used, but are not preferred. Identify the diskette by providing journal name, manuscript number, senior author's name, manuscript title, name of computer file, type of hardware, operating system and version number, and software program and version number.

The Journal does not assume responsibility for errors in conversion of customized software, newly released software, and special characters. Mathematics and tabular material will be processed in the traditional manner. 